\title{
Investigating the capacity of self and peer assessment activities to engage students and promote learning
}

\author{
Keith Willey ${ }^{1}$ and Anne Gardner ${ }^{2}$
}

Faculty of Engineering and IT, University of Technology, Sydney, Sydney, Australia

${ }^{\mathrm{a}}$ Faculty of Engineering \& IT, University of Technology, Sydney

PO Box 123 Broadway, NSW 2007 Australia,

Ph: +61295147605 Fax: +61295142435 email:keith.willey@uts.edu.au

*Corresponding Author

${ }^{\mathrm{b}}$ Faculty of Engineering \& IT, University of Technology, Sydney

PO Box 123 Broadway, NSW 2007 Australia,

Ph: +61295142622 Fax: + 61295142633 email:Anne.Gardner@uts.edu.au.

(Received 24th December 2009; final version received 12th April 2010)

Wordcount including references: 6640

\begin{abstract}
The authors have previously reported the effectiveness of using self and peer assessment to improve learning outcomes by providing opportunities to practise, assess and provide feedback on students' attribute development. Despite this work and the research of others, a significant number of students and indeed many academics focus on the freerider deterrent capability of self and peer assessment, rather than its capacity to provide opportunities for developing judgement and facilitating reflection and feedback to complete the learning cycle. The advent of web-based tools such as SPARK ${ }^{\text {PLUS }}$ allows the frequent and efficient implementation of self and peer assessment activities even in large classes. This article reports the results of an investigation as to whether the regular use of self and peer assessment in different contexts promoted effective peer learning, increased engagement and encouraged students to learn.
\end{abstract}

Keywords: self and peer assessment, teamwork, collaborative peer learning, SPARK ${ }^{\text {PLUS }}$

\section{Introduction}

The authors have previously reported the effectiveness of using self and peer assessment to improve learning outcomes by providing opportunities to practise, 
assess and provide feedback on students' attribute development. Despite this work and the research of others, many students (and academics) perceive self and peer assessment to be mainly an instrument to facilitate fairness, focusing on its free-rider deterrent capacity in group assessment tasks, rather than providing opportunities for reflection and feedback to complete the learning cycle (Willey and Gardner 2008a).

In previous research the authors found that many students in well functioning teams often commented that they had little to discuss in regard to their self and peer assessment results, even though being guided through a feedback process, as they believed that everyone in the team had contributed fairly. Typically they did not take the opportunity to discuss how they could have improved their work and hence missed the opportunity to benefit from feedback that would assist their ongoing professional development or potentially improve their grade in subsequent assessment tasks or subjects. Furthermore, nearly a quarter of students in well functioning teams reported that they did not think self and peer assessment improved their group work experience (Willey and Gardner 2008a, Willey \& Freeman 2006a).

It is the authors' intention that all students would benefit, both from the reflective nature of self and peer assessment and the feedback it provides, and for these benefits to be seen as valuable and desirable so that students are eager to participate.

This article reports on the integrated use of self and peer assessment in an Engineering Design subject. Self and peer assessment was used not only to assess team contributions, but to assess individual student assignments and in benchmarking exercises. In particular, this research investigates if exposing students to the use of self and peer assessment for different purposes, providing them with multiple 
opportunities to practise and receive feedback in different contexts, promoted effective peer learning, increased engagement and encouraged students to learn.

\subsection{Background}

The use of self and peer assessment has been widely reported in the literature (Goldfinch 1994, Goldfinch \& Raeside 1990, Falchikov \& Goldfinch 2000). In addition to providing fairer assessment of group work, self and peer assessment is reported as assisting students to develop important professional skills including reflection and critical thinking (Mello 1993, Somervell 1993). Michaelsen discusses the use of self and peer assessment to promote peer learning (Michaelsen et al. 2004), while Hanrahan and Isaacs (2001) report that it contributes to students' development of critical thinking skills and motivates students to submit better initial submissions knowing they would be reviewed by their peers. Willey and Freeman (2006a, 2006b) report using self and peer assessment to produce formative learning-oriented feedback to complete the learning cycle and encourage the ongoing development of skills. Furthermore, Boud and Falchikov (2007) discuss its use for developing students' skills for lifelong learning. More recently the authors have reported the effectiveness of using self and peer assessment to improve learning outcomes by providing opportunities to practise, assess and provide feedback on students' graduate attribute development (Willey and Gardner 2008a).

Recently momentum has grown for assessment to change from 'assessment of learning' to 'assessment for learning' (Torrance 2007). Learning-oriented assessment embeds learning in assessment, reconfiguring its design to emphasise the function of learning (Keppell \& Carless 2006; Keppell et al 2006). Its three main elements (Carless 2007, Black \& Wiliam 1998) are:

(1) assessment tasks that focus on learning 
(2) involving students in the assessment process to develop their graduate attributes including judgement

(3) feed-forward to improve subsequent contributions and learning.

Rust et al (2005 pg243) report "that of the whole assessment process, the research literature is clear that feedback is arguably the most important part in its potential to affect future learning and student achievement". However, feedback is often provided long after the assessable work has been completed, at which time students may no longer be interested, instead being focused on the next assessment task. Hence, for feedback to be productive and used for student reflection, it must be both timely and focused.

However, while the provision of detailed feedback and assistance by instructors typically leads to higher quality student submissions, care needs to be taken. The authors have noticed a tendency for some students to become 'incremental learners' whereby they seek ongoing direction from academic staff to improve their submission. It occurred to us that some students were not exercising their own judgement but rather simply implementing what they were told. Their focus being on securing a better grade by giving the instructor exactly what they want, without question, rather than learning from or even understanding the feedback provided. Hence, there is a danger that ongoing feedback if not focused correctly (to inspire and motivate students to learn rather than circumvent their reflection and thinking), may encourage dependent rather than independent learning. Furthermore, a reliance on the academic's judgement reduces both the challenge of the learning process and the legitimacy of the assessment (Torrance 2007). In contrast, peer learning encourages students to take more responsibility for their own learning (Keppell et al. 2006). 
Self and peer assessment would appear to be an ideal tool to facilitate learning oriented assessments. It has the capacity to encourage students to take more responsibility for their own learning by requiring them to provide their own feedback, contribute to their own assessment and to the assessment of their peers. Having students provide feedback improves their judgement, assessment ability and critical evaluation skills. Since students provide the feedback themselves they have to use their judgement to determine both the validity of the feedback and how they should respond, addressing the 'incremental learner' concerns discussed above. Furthermore, since typically each student only assesses a small number of their peers, feedback can be both timely, frequent and focused (by the use of appropriate criteria) without undue burden. We recommend concluding these learning activities with academic feedback to complete the learning cycle. With careful design such activities can also change students' attitude to learning and introduce them to the different modes of learning. In addition, we believe students need opportunities to practise and test their knowledge to first identify then rectify gaps in their learning. The authors encourage students to push their learning boundaries and not to be scared to make mistakes. Our motto is 'mistakes compress learning' and we aim to provide opportunities for students to make mistakes (initially with low risk), understand why they are incorrect, and then apply this knowledge to new situations and contexts to produce new learning. The regular use of self and peer assessment provides opportunities for students to practise, test, receive feedback on and develop their judgement, an essential attribute for lifelong learning (Boud \& Falchikov 2007).

In previous research Willey and Freeman (2006a, 2006b) reported their use of an online tool called SPARK® (Freeman \& McKenzie 2002), to facilitate confidential 
self and peer assessment and focus students' efforts on learning and practicing the skills required for teamwork.

For several years the authors have used self and peer assessments, collected using the online tool SPARK®, to not only promote the development of professional skills but to facilitate the provision of regular feedback in large engineering classes. In previous research self and peer assessment was found to improve students' groupwork experience, reduce the instances of free-riders and encourage students to improve their professional skill development (Willey \& Freeman 2006a, 2006b). Students reported that the use of self and peer assessment, together with criteria that specifically assessed teamwork processes, had encouraged team cooperation, commitment and increased individual student engagement.

This research identified the need to expand the functionality of SPARK® and with a group of other developers (see acknowledgements) a new version of SPARK® known as SPARK ${ }^{\text {PLUS }}$ was developed (Willey and Gardner 2008b, 2008c). SPARK $^{\text {PLUS }}$ is capable of facilitating the use of self and peer assessment to not only assess a student's contributions to a team project, but also allows students to self and peer assess individual work and improve their judgment through benchmarking exercises. In addition, the program's ability to report results was extended by adding the capacity to provide marks as well as the formative and summative assessment factors produced by the original SPARK. SPARK ${ }^{\text {PLUS }}$ also has the capacity to provide this feedback in a number of different graphical representations.

\section{SPARK ${ }^{\text {PLUS }}$}

SPARK $^{\text {PLUS }}$ (Willey 2010) assists participants in making their self and peer assessments by requiring them to rate each other over multiple criteria (Figure 1). Unlike other self and peer assessment packages, SPARK ${ }^{\text {PLUS }}$ has the capacity to 
produce three assessment factors (for more details see the SPARK ${ }^{\text {PLUS }}$ user guide Willey 2010). The first factor known as the Self and Peer Assessment or SPA factor is a weighting factor determined using one of three available formulas from both the self and peer rating of a student's contribution:

$$
\text { SPA Factor } \propto \frac{\text { Total ratings for individual team member }}{\text { Average of total ratings for all team members }}
$$

It is typically used to change a team mark for an assessment task into an individual mark as shown below:

$$
\text { Individual mark = team mark x Individual's SPA factor }
$$

The second factor is the Self Assessment to Peer Assessment or SAPA factor. This is the ratio of a student's own rating of themselves compared to the average rating of their contribution by their peers:

$$
\text { SAPA Factor }=\sqrt{\frac{\text { Self ratings for individual team member }}{\text { Average of ratings for individual by peer team members }}}
$$

The SAPA factor compares a student's self assessment to the assessment of their contribution and/or submission by their team peers. It has strong feedback value for development of critical reflection and evaluation skills. For example, a SAPA factor greater than 1 means that a student has rated their own performance higher than the average rating they received from their peers and vice versa.

The third factor is a percentage mark, the calculation of which depends on the type of task that has been selected (e.g. benchmarking exercise or marking individual work).

SPARK $^{\text {PLUS }}$ allows students to provide anonymous written feedback to their peers (Figure 1) as well as providing a number of options for graphical feedback, two of which are shown in Figures 1 and 2. In Figure 1, in addition to the assessment 
factors, the instructor has chosen to provide students with feedback in regard to the differences between their own self assessments and the average assessment of their performance by their peers for each individual criterion. Referring to Figure 1 the upper triangle shows the student's self rating for each individual criterion, while the lower triangle shows the student's average rating for each criterion received from their team peers. These triangles provide students with detailed formative feedback on their performance in regard to each individual criterion.



Figure 1. A student's SPARK ${ }^{\text {PLUS }}$ results screen for a task where each student had to self assess their own submission and assess the individual submissions of their team peers.

In Figure 2(a) and (b) the factors are displayed as radar diagrams which identifies a student's strengths and weaknesses for different assessment categories. Their performance, relative to their peers in a particular category is depicted by the position of the SPA factor envelope compared to 1, while the SAPA envelope identifies any discrepancies between a student's self perceptions and the perceptions 
of their performances by their peers. The recording of these diagrams in an eportfolio may assist students to track their attribute development throughout their degree program.

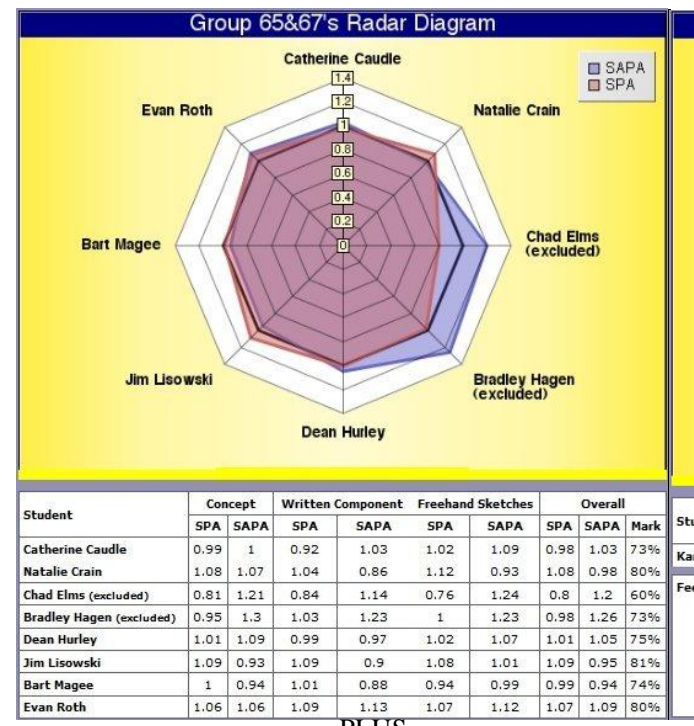

Figure 2(a). SPARK ${ }^{\text {PLUS A Group }}$

Radar Diagram and table for the task in Figure 1.

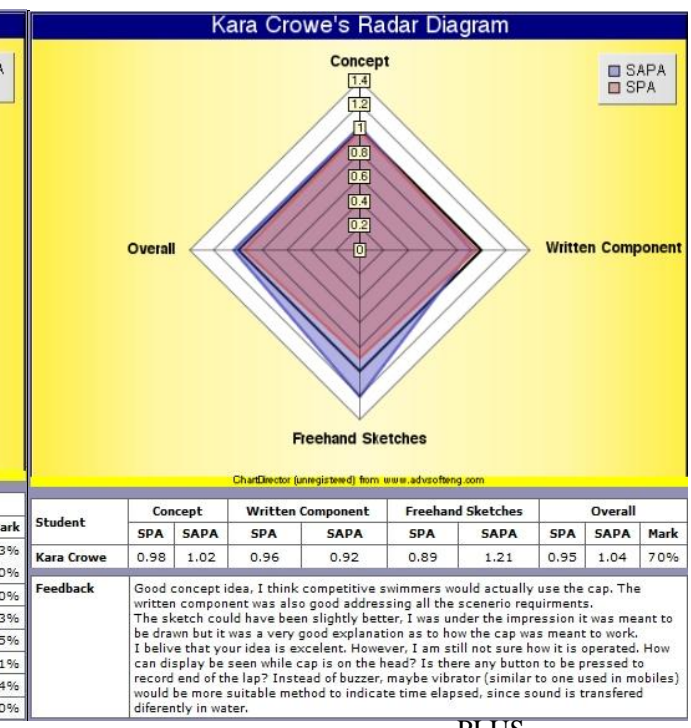

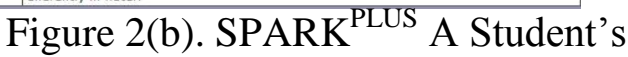
individual Radar Diagram and comments for the task in Figure 1.

The diagram in Figure 2(a) is a group radar diagram for an assessment task where each student assessed their own submission and each individual submission of their team peers. The diagram in Figure 2(b) is an individual radar diagram which shows a particular student's performance in a number of categories and also reports written peer feedback.

SPARK $^{\text {PLUS }}$ has many additional features including a choice of different algorithms to calculate both the SPA factor and a student's percentage marks, the selection of which depends on the design of the assessment task and the desired learning outcome. The program also contains management features to assist academics in identifying saboteurs, free riding students and teams that may be experiencing some dysfunction. For more information on SPARK ${ }^{\text {PLUS }}$ please refer to the webpage at http://spark.uts.edu.au (Willey 2010). 


\section{Design Fundamentals}

Design Fundamentals is a Stage 3 compulsory core subject undertaken by students from all engineering disciplines at the University of Technology, Sydney. The subject's typical cohort is approximately $300+$ students with tutorial classes being limited to a maximum of 32 students.

The subject's primary aims are to:

(1) Develop students' understanding of the engineering design process

(2) Provide students with the skills to develop a small engineering project from initial concept to the production of a prototype.

(3) Continue the development of students' professional skills including teamwork, critical evaluation, judgement, feedback and communication commenced in earlier subjects.

To promote the development of professional skills, provide students with feedback, improve student's judgement and critical evaluation skills, encourage both academic honesty and students to take responsibility for their own learning, a process of self and peer assessment (collected using the online tool SPARK ${ }^{\mathrm{PLUS}}$ ) is used four times during the semester. The results of these assessments are used to:

(1) Provide constructive feedback to students on their skills and performance in both individual and group tasks.

(2) Promote peer collaboration and learning.

(3) Develop student critical evaluation, judgement and feedback skills.

(4) Allow students to assess their ongoing skills development and identify their individual strengths and weaknesses.

(5) Provide students with an opportunity to learn from this feedback to improve subsequent performance.

(6) Determine marks for individual submissions. 
(7) Determine individual assignment marks by appropriate adjustment of group marks.

The authors' intention is to use self and peer assessment processes to move students from being novice to become more expert in their development as they progress through the subject and subsequently through their degree. To achieve this we have an intentional focus on using results to facilitate the provision of feedback. Students are provided with the percentage mark (if applicable), SPA and SAPA factors for themselves and each of their group members. After allowing sufficient time for students to personally reflect on the assessments, each group is guided through a feedback process (Willey \& Freeman 2006a, Willey and Gardner 2008c).

Providing opportunities for students to practise, followed by feedback multiple times a semester, affords students an opportunity to test both their judgement and what they have learnt, and then reflect to improve their performance. Students are actively encouraged by their tutors to view using self and peer assessment as a learning opportunity in which participation will not only assist them in learning, developing their professional skills and provide feedback, but also help them to produce a better project.

\section{Method}

Self and Peer assessment was integrated into four distinct peer learning assessment tasks that combine to form a major design project. The tasks were as follows:

(1) Individual Project Concept: Students use SPARK ${ }^{\text {PLUS }}$ to assess their own and seven of their peer's submissions, rating each student's individual product concept developed to meet a number of specified criteria (approx $1.5 \mathrm{hrs}$ ). In the next tutorial ( 2 to 3 hours) the group of eight students debate the merits of each individual submission (discussing their individual strengths and weaknesses) and 
collectively place them in order from best to worst, awarding a mark for each. Students then receive the results from SPARK ${ }^{\text {PLUS }}$ and are asked to reflect on any differences between results produced from their individual assessments $\left(\right.$ SPARK $\left.^{\text {PLUS }}\right)$ and those produced collectively in their peer group. The tutor marks and provides feedback (to complete the learning cycle) on one report from each group and determines the marks for the other reports using the weighting produced by SPARK ${ }^{\text {PLUS }}$.

The peer learning groups are divided into two groups of four students. These groups of four students then work together to complete the design project.

(2) Benchmarking Exercise: Students are provided with a Sample Requirement Specification report produced by a student group from a previous semester. After discussing the marking criteria each student has to individually assess the report using SPARK ${ }^{\text {PLUS }}$ (approx 45 minutes). These are the same criteria that will be used by tutors to mark each group's Requirements Specification report submitted later in the semester. In their next tutorial (approx 2 hours) each group of four students discuss their marking of the report and re-mark it collectively against the criteria. Students then re-combine into their peer learning groups (two groups of four students) and discuss their group's marking of the report, reflecting on any differences and collectively re-mark it. Tutors then discuss how they marked the report. After the tutorial students may log on to SPARK ${ }^{\text {PLUS }}$ and compare their individual marking to the instructor's marking of the report for each individual criterion. In addition, SPARK ${ }^{\text {PLUS }}$ produces a mark based on how close the student's individual assessment was to the academic's assessment.

(3) Requirement Specification Report: each group of students produces a Requirement Specification report for their selected product. Students use 
SPARK $^{\text {PLUS }}$ to rate their own and their team peers' contribution to this stage of the project. The SPARK ${ }^{\text {PLUS }}$ SPA factors are used to produce individual marks by moderating the mark for the group's submission. The group's radar diagrams and a table of categorised factors (similar to Figure 2a) are distributed to each group and discussed in the next tutorial. Groups are guided through a feedback process. This process begins with students sharing positive feedback with the focus not just being on what their peers did well but also on what they learnt from their peers. This is followed by a process of self evaluation where students share with their group what they have learnt or discovered about their strengths, weaknesses or performance from the exercise. Students are encouraged to identify how they could improve their own performance and in what way they would approach the task differently if they had to do it again. The final stage in the feedback process is the provision of constructive criticism to team peers. Students are asked to suggest how others in their group may have approached their tasks differently to achieve a better group result, how aspects of their behaviour affected the team, the benefits of changing that behaviour, and to reflect on how team peers could have learnt more from the process. Furthermore, students are asked to share what they consider to be the weaker aspects of a peer's contribution and how this could have been improved.

The in-class discussion (approx 1 hour) concludes by teams agreeing how to improve their overall team and individual performance for the remaining parts of the project and /or in future group work opportunities.

(4) Project Report, Oral Presentation and Prototype Demonstration: each group of students produce a project report, make an oral presentation and present their prototype design. Students again use SPARK ${ }^{\text {PLUS }}$ to rate their own and their team 
peers' contribution to this stage of the project. This is followed by the same feedback process and discussion as previously described for the Requirement Specification report (approx 1 hour).

In Spring semester 2008 a number of subject surveys were conducted to assess the effectiveness of the self and peer assessment processes used. The questions in all surveys were a mixture of free response and 4 point Likert format. While all students undertaking the project (eligible cohort 255, some repeating students complete different activities) were required to participate in the assessment exercises, in accordance with our ethics approval, participation in the surveys was voluntary. The first two surveys (Individual Project Concept and Benchmarking) were conducted in tutorial classes resulting in 209 and 200 students responding respectively. The post subject survey was much longer, covering a number of topics, conducted online just before the exam period and took students at least 30 to 45 minutes to complete. Of the eligible cohort, 89 students (35\%) volunteered to complete the online survey.

\section{Results and Discussion}

The survey results relevant to this paper are shown in Figures $3-7$. Where applicable the 'Strongly Agree' and 'Agree' responses were combined to give an aggregate result, as were the 'Strongly Disagree' and 'Disagree' responses. The percentage of any unanswered questions are generally not shown but can be calculated by subtracting the provided results from $100 \%$.

The results presented in Figure 3, show that the majority of students (ranging from $78 \%$ to $91 \%$ ) believed that all aspects of the group marking of individual submissions improved their ability to choose and report on a product concept. While this does not mean that the self and peer assessment processes used cannot be improved, it does demonstrate that each distinct process within each assessment task contributed 
significantly to improving a student's ability to achieve the prescribed learning outcomes.

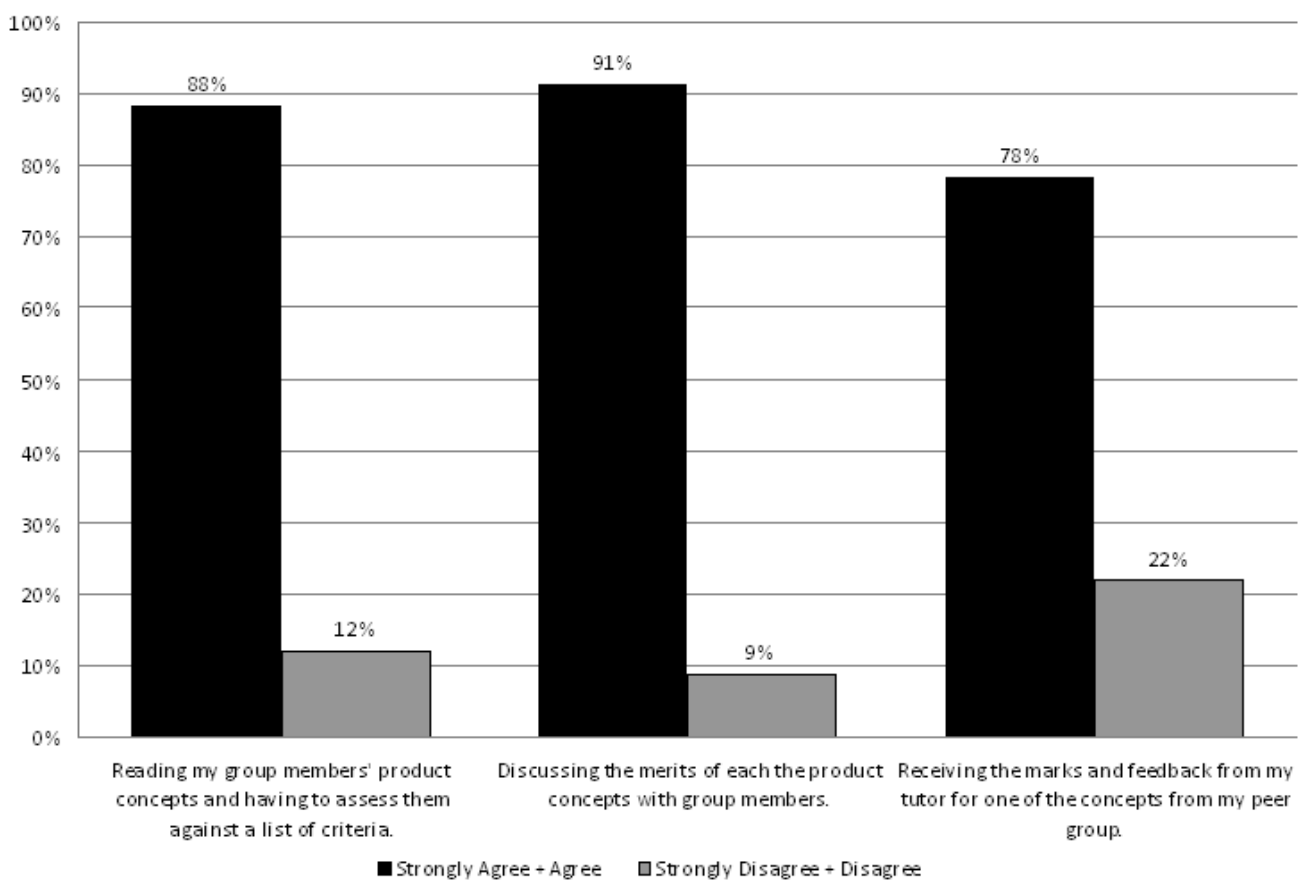

Figure 3. Results from student survey of Self and Peer Assessment Marking of Individual Project Concepts in response to the question "My ability to choose a product concept and write a concept document to meet a list of requirements increased as a result of:"

Students (47\%) in the individual project concept exercise reported that discussing the different concepts in the group was the most effective part of the exercise in improving their understanding and ability (Figure 4). This was followed by reading the reports themselves and assessing them against the criteria (31\%). Somewhat surprisingly only $17 \%$ of students reported that their tutor's explanation of their marking of an exemplar was the major contributor to improving their understanding and ability of this particular exercise.

The results reported in Figure 5 show that students believed that all aspects of the benchmarking exercise improved their ability to write a Requirement Specification report. In the benchmarking exercise $37 \%$ of students reported that discussing the specification marking within the group and then re-marking it 
collaboratively was the part of the process that improved their understanding and ability the most (Figure 6). This was followed by discussing and re-marking the report within the combined group (25\%) and feedback guidance and explanation from the tutor $(23 \%)$. Only $14 \%$ of students reported that their understanding and ability was most improved by reading and assessing the specification by themselves.

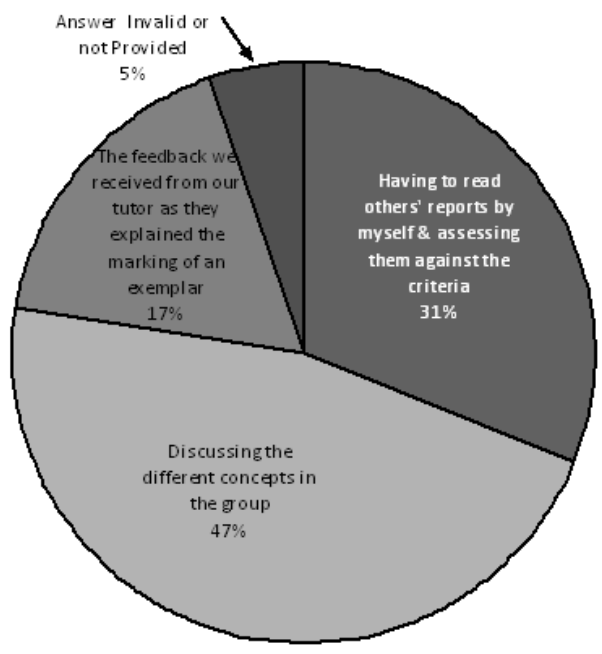

Figure 4. Results from student survey of Self and Peer Assessment Marking of Individual Project Concepts in response to the question: "Which part of the whole process improved your understanding / ability the most?"

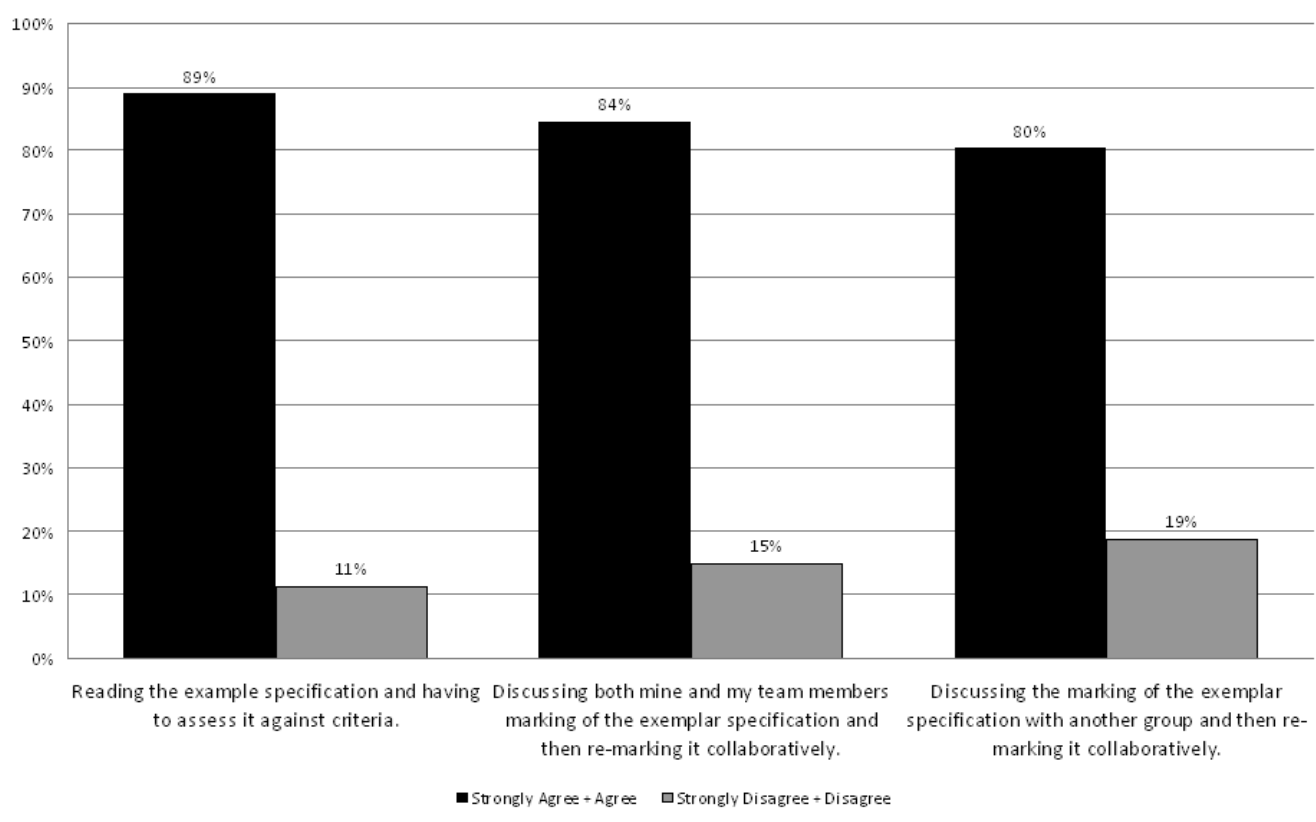

Figure 5. Results from student survey of Self and Peer Assessment Benchmarking Exercise in response to the question "My ability to write a quality requirement specification has increased as a result of:" 


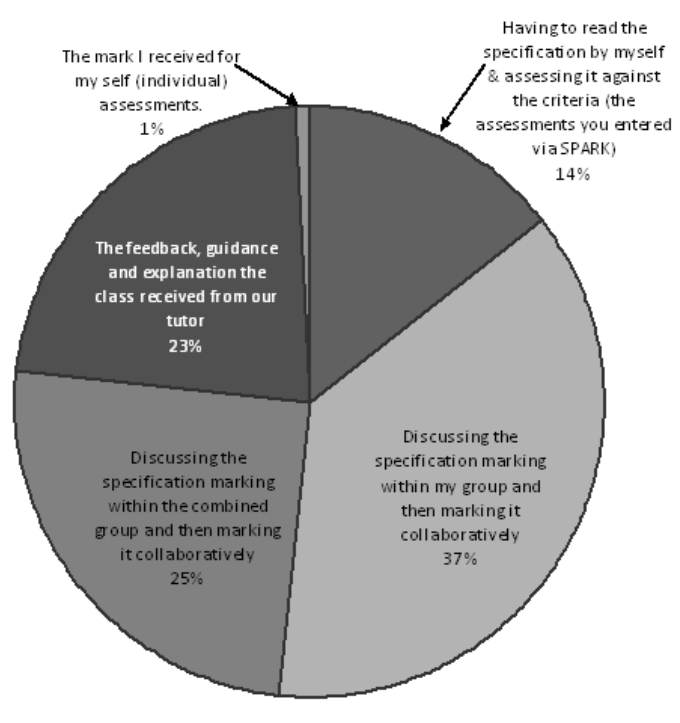

Figure 6. Results from student survey of Self and Peer Assessment Benchmarking Exercise in response to the question "Which part of the whole process do you feel improved your understanding / ability the most?"

While the fact that students found different parts of these tasks to be the most beneficial in improving their understanding and ability may be partly explained by differences between individual learning styles, the results do suggest that collaborative peer learning activities are generally the most beneficial. Conversely the fact that $31 \%$ (individual project concept marking) and 14\% (benchmarking exercise) of students reported that individual work provided them with the most benefit supports the deliberate intention to design collaborative learning oriented assessment tasks that accommodate students' diverse learning styles and abilities by providing a number of different opportunities that build on each other to learn.

An aspect that should be considered in interpreting these results is that it tends to be the middle activity in these exercises that most students felt provided the most benefit. This is not surprising as students develop some understanding in the individual segment of the task, they build on this learning and explore their understanding in the collaborative group exercise while the last component involving 
interaction with the tutor happens after most of the learning has already occurred and serves mainly to clarify any outstanding questions and issues.

Furthermore, the group discussion exercises are specifically designed to promote peer collaboration. For example in the individual project concept exercise, the marking scheme is such that it is in each student's interest to honestly grade each concept rather than to just argue for their own idea as the best group outcome occurs when their marking aligns with the tutor's (academic moderation is achieved by the tutor marking one report from each group and then using this to calibrate the marks received for the other submissions). The group discussion activity is also different to other parts of the process in that it has a social element, which tends to promote engagement. The process of individually marking the work using SPARK ${ }^{\text {PLUS }}$ before the tutorial means most students come to class prepared, having already thought about the assessed work. This promotes high engagement, enabling students to make useful contributions to the discussion and for discussions to quickly focus on areas where there was a difference of opinion. While receiving feedback from the tutor has a personal communication element, this interaction is quite different to the interaction that students have with each other, and probably not as much fun. We acknowledge that the surveys only collect students' subjective perceptions as opposed to an objective test of their learning, so the element of enjoyment and engagement may bias their perceptions of where their learning occurred. For example, it is reasonable to suggest that if the collaborative discussion part of the process is where students are most engaged and have the most fun, then this probably contributes to the perception that this is the part of the activity in which they learnt the most. Irrespective of any potential bias the fact remains that the success of these activities in improving student 
engagement and learning hinges on the opportunity to have these collaborative conversations.

Prior to the exercises tutors discuss with students the learning opportunities available. These vary from teaching others and in the process improving their own understanding, to being taught by their peers. It is our experience that most students adopt a combination of these roles, but we strongly encourage students that feel they have nothing to learn from their peers to take the opportunity to teach. Students have reported that in the process of teaching their peers they have discovered gaps in their own learning, in some cases even reported discovering that they didn't really understand the material at all and, hence, during the exercise switched roles from the teacher to the one being taught.

While there were some complaints from students that it took too long to complete all the parts of the exercises, an issue that is being addressed in the activity design, generally speaking most students were positive in line with the survey free response comments below:

\section{Individual project concept:}

"Allows you to see what people think of your work and how you can improve" [sic].

"Tutorial was beneficial because it allowed 2 different groups to assess project concept. It was a good way to review because a variety of answers were provided towards the Individual Concept."

\section{Benchmarking:}

"Reviewing and marking a previous piece of work helped to understand the theory from the lectures. Knowing we need to write a Requirements Specification that is unambiguous is easy enough to know, but WHAT that actually looks like, and doing it 
is hard. Getting a picture of what NOT to do first, helps developing that knowledge" [sic].

A small number of students in the Individual project concept exercise reported that they did not believe students should be involved with assessing each other's work. A number of reasons were provided including believing they did not have the knowledge or skill to make fair assessments, they had no confidence in the assessments or feedback provided by their peers or they thought it was not their responsibility and hence they should not be required to do it. These attitudes are evident in the following free response comments:

"There should be less emphasis on other students marking your concept. I found some people were lazy and did not give each concept equal time to mark and overlooked some. It should be more a person who thoroughly knows the marking criteria (ie tutor) who has more weighting."

"Students mark should be based on the mark given to them by their tutors. This is what we are paying them to do."

The fact that students feel uncomfortable, or felt they and/or their peers lacked the judgement to assess each other's work, is the very reason why such tasks should be a regular part of learning activities. Students need opportunities to practise using and receiving feedback on their judgement. Most academic staff can still remember their uncertainty the first time they had to grade papers with confidence in our own judgement growing the more we participated in (ie. practised) such activities. As previously stated mistakes compress learning - if students do not regularly practise making assessments, exercising their judgement and reflecting on the results, these skills will remain underdeveloped. 
In addition, through our observations of the two previously described collaborative exercises we formed the opinion that conversations were the mechanism that promoted learning. The collaborative conversations were a timely forum for students to test and receive feedback on their knowledge and understanding. Frequently, when feedback is given, students do not respond to or test their understanding of the feedback until well after it has been provided. Often in the case of endpoint assessments this understanding remains untested. The collaborative exercises allow students to test their judgement, receive feedback and explore their understanding in a relatively short time frame. The collaborative conversations appeared to help students embed their learning, transforming it from untested opinion to knowledge that could then be applied in new contexts to create new learning.

Figures 7(a) and 7(b) report the results for the two self and peer assessment exercises used to determine a team member's contribution to the last two stages of the project. The results suggest that the use of self and peer assessment made a significant contribution to students' engagement and learning, with $74 \%$ of respondents agreeing that it encouraged them to put more consistent effort into their assigned work, $73 \%$ agreeing it improved their ability to make assessments, $75 \%$ agreeing it improved their ability to both give and receive feedback, 69\% agreeing that the feedback they received improved their contribution and 60\% agreeing that this feedback will help them build on their strengths and address their weaknesses. Furthermore, $65 \%$ of respondents agreed that the self and peer assessment processes added value to the group work experience. These results are particularly encouraging given our aim to see students eager to participate in self and peer assessment processes as a result of finding them valuable and desirable. 


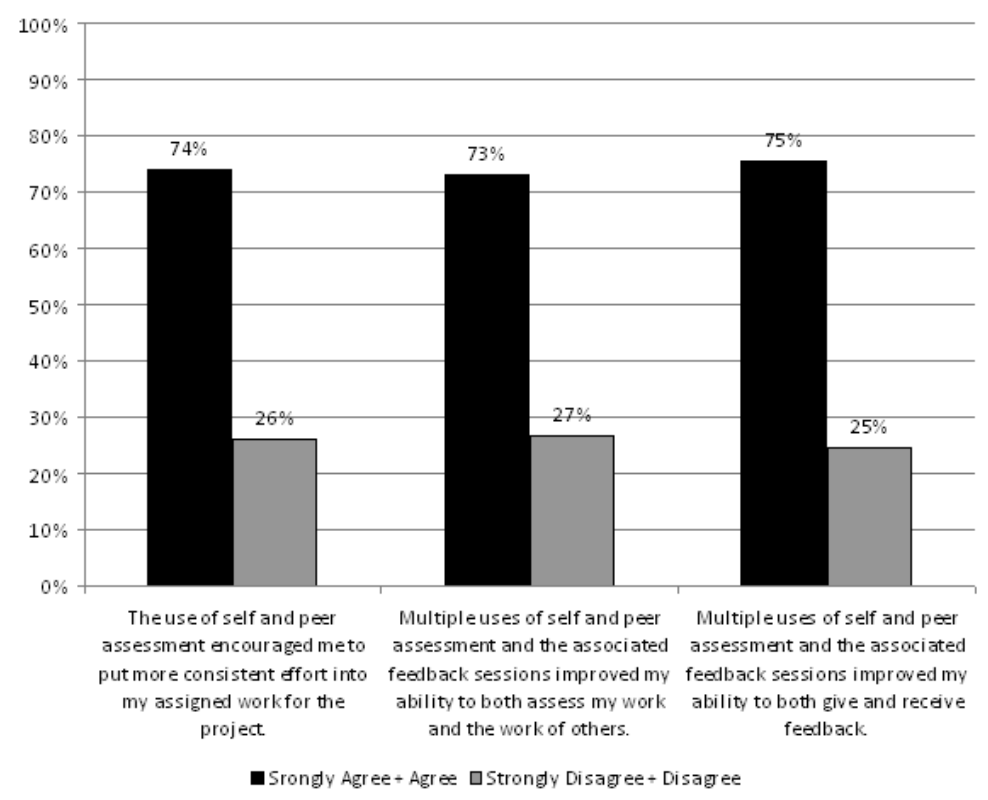

Figure 7(a). Results from student post-subject survey.

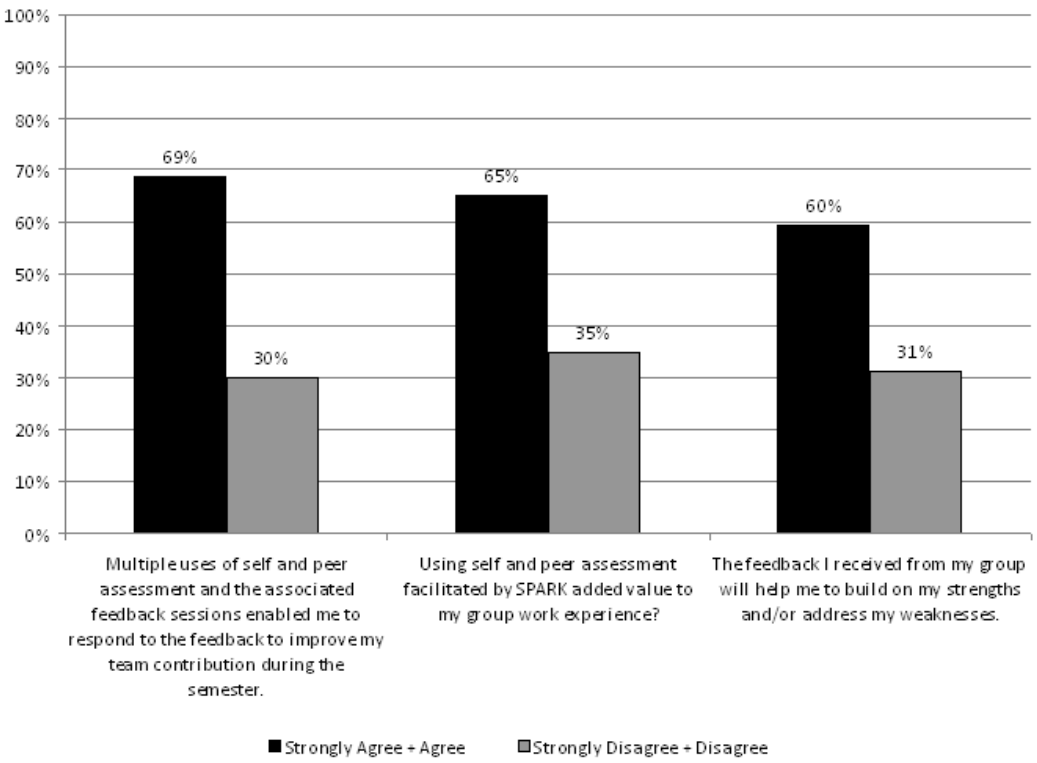

Figure 7(b). Results from student post-subject survey.

The vast majority of the survey free response comments were positive, as typified by the following comments:

"Peer assessment facilitated by SPARK improved my group work experience by facilitating and giving me peer feedback with regards to the contributions by the team. It gave all team members an opportunity to give fair and constructive feedback 
(mostly) to each other, thus improving the performance in projects throughout the semester, and most likely in later subjects also."

"Improved my group work experience as SPARK enables a fairer assessment, I was driven to participate and function with my team as a group. It gave me the opportunity to see my effort (by my SPA rating) and also to know what other team members thought about my performance from feedback received. I really enjoyed working in a group for this subject and I think SPARK had a big influence in that" [sic].

However, a small minority of free response comments like those below highlighted issues to be considered in the design of future assessment tasks:

"I feel SPARK did not improve my group work experience, $i$ was lucky enough to have a group of great guys, where we took it upon ourselves to work as a team, it may have affected my experience greatly if $i$ had group members that did not do their share." [sic]

"It's still difficult to give negative feedback, for fear of people being defensive and resentful."

Feedback couldn't be used to improve mistakes and consequently improve the assessment marks. I feel its a big waste when this is the case as the feedback isn't taken as serious as it should be as you cant use it to improve your marks. Even though it helps you to learn, as it doesn't show through in the assessment marks which is ultimately the students number 1 aim,...." [sic].

The overall results support the conclusion that using self and peer assessment to provide multiple opportunities to practise and receive feedback in different contexts encouraged peer learning, increased engagement and students' desire to learn. However, the above comments indicate that there are still students who regard the 
major function of self and peer assessment as being to deter free-riders. This perception needs to be changed if students are to receive the potential benefits from the feedback these processes provide. It was also apparent that students need more training and support to develop their team skills, in particular dispute or conflict resolution, and the ability to give constructive feedback.

As part of our response to these findings SPARK ${ }^{\text {PLUS }}$ is currently being expanded to facilitate students receiving a grade for the quality and usefulness of feedback they provide to group peers. It is our opinion that given the competitive nature of some students, unless the quality of the feedback they provide is assessed, they may be reluctant to provide beneficial feedback to tasks that allow resubmission, for fear of helping a fellow student to exceed their own final grade. While this situation is not ideal, with our aim being for students to focus on learning and not grades, for this to occur the attitude of many students needs to change - as indicated in the last free response comment for some improving their grade "is ultimately the student's number 1 aim”.

\section{Conclusion}

The results show that the multiple use of self and peer assessment processes for different purposes within a single subject was successful in assisting students in achieving the desired learning outcomes. In general, students reported that the feedback they received, in a number of different contexts, particularly in the peer learning exercises, increased engagement and successfully supported them to learn. However, we found that more effort is required to break down the reluctance of some students to assess their peers and to change the narrow focus of some students that self and peer assessment is only a tool to facilitate fairness. This study also found that while the new features provided in SPARK ${ }^{\text {PLUS }}$ were successful in improving the 
available outcomes from using self and peer assessment, particularly in large classes, more improvements are required, such as the facility to assess feedback, to complete the learning cycle.

\section{Acknowledgements}

The redevelopment of SPARK was a joint research project between the University of Technology, Sydney and the University of Sydney. The main developers were Dr Keith Willey UTS, A/Prof Mark Freeman USyd (also chief architect and developer of the original SPARK) and Mr Darrall Thompson UTS. We would also like to acknowledge the contribution of Mr Mike Howard who has continued to work with the authors in developing SPARK ${ }^{\text {PLUS }}$.

\section{References}

Black P. \& Wiliam D. (1998) Assessment and classroom learning Assessment in Education: Principles, Policy \& Practice; Mar1998, Vol. 5 Issue 1, p.7

Boud D., and Falchikov, N.( 2007) Rethinking Assessment in Higher Education Learning for the Longer Term. Routledge.

Carless D. (2007) Learning-oriented assessment: conceptual bases and practical implications Innovations in Education and Teaching International Vol. 44, No. 1, February 2007, pp. 57-66

Falchikov, N., and Goldfinch, J. (2000). Student Peer Assessment in Higher Education: A Meta-Analysis Comparing Peer and Teacher Marks. Review of Educational Research, 70(3), 287-322.

Freeman M. and McKenzie J. (2002), SPARK, A Confidential Web-Based Template for Self and Peer Assessment of Student Teamwork: Benefits of Evaluating across Different Subjects, British Journal of Educational Technology, vol. 33, pp. 551-69.

Goldfinch, J. (1994). Further developments in peer assessment of group projects., Assessment \& Evaluation in Higher Education Vol. 19, pp. 29: Carfax Publishing Company.

Goldfinch, J., and Raeside, R. (1990). Development of a Peer Assessment Technique for Obtaining Individual Marks on a Group Project. Assessment and Evaluation in Higher Education, 15(3), 210- 231.

Hanrahan S. \& Isaacs G. (2001) Assessing Self- and Peer-assessment: the students' views Higher Education Research \& Development, Vol. 20, No. 1 pp. 53 -70.

Keppell M. \& Carless D. (2006) Learning-oriented assessment:a technology-based case study Assessment in Education Vol. 13, No. 2, July 2006, pp. 179-191

Keppell. M., Au E., Ma A., \& Chan C., (2006) Peer learning and learning-oriented assessment in technology-enhanced environments Assessment \& Evaluation in Higher Education Vol. 31, No. 4, August 2006, pp. 453-464

Mello J. A. (1993). Improving individual member accountability in small work group settings, Journal of Management Education, vol. 17(2), pp. 253-259, 1993.

Michaelsen L, Knight A., Fink L., (2004) Team-based Learning - A transformative use of small groups in college teaching. USA, Sylus Publishing. 
Rust, C., O’Donovan, B., \& Price, M. (2005). A social constructivist assessment process model: how the research literature shows us this could be best practice. Assessment \& Evaluation in Higher Education 30(3), 231-240.

Somervell H. (1993). Issues in assessment, enterprise and higher education: the case for self-, peer and collaborative assessment, Assessment \& Evaluation in Higher Education,vol.18, pp.221-233,1993.

Torrance H. (2007) Assessment as learning? How the use of explicit learning objectives, assessment criteria and feedback in post-secondary education and training can come to dominate learning. Assessment in Education Vol. 14, No. 3, November, pp. 281-294

Willey K, and Freeman M. (2006a), Improving teamwork and engagement: the case for self and peer assessment, Australasian Journal of Engineering Education. Online publication 2006-02 http://www.aaee.com.au/journal/2006/willey0106.pdf

Willey, K. and Freeman M. (2006b), Completing the learning cycle: The role of formative feedback when using self and peer assessment to improve teamwork and engagement. Proceedings of the 17th Annual Conference of the Australasian Association for Engineering Education, 10 -13th December 2006, Auckland, New Zealand.

Willey K \& Gardner A. (2008a) Using Self Assessment to Integrate Graduate Attribute Development with Discipline Content Delivery. Proceedings of the $36^{\text {th }}$ Annual Conference of the European Association of Engineering Education (SEFI) 2-5 July, Aalborg, Denmark.

Willey K \& Gardner A. (2008b) Improvements in the self and peer assessment tool SPARK: Do they improve learning outcomes? Proceedings of the ATN Assessment Conference - Engaging Students in Assessment, 20-21 November, Univ. of South Australia, Adelaide, Australia.

Willey K \& Gardner A. (2008c) Using self and peer assessment for professional and team skill development: do well functioning teams experience the benefits? Proceedings of the ATN Assessment Conference - Engaging Students in Assessment, 20-21 November, Univ. of South Australia, Adelaide, Australia.

Willey K (2010) SPARK ${ }^{\text {PLUS }}$ webpage The University of Technology, Sydney http://www.spark.uts.edu.au/ last visited 10 April 2010. 